\title{
Tide and Mixing Characteristics in Sundarbans Estuarine River System
}

\author{
Goutam KS ${ }^{1 *}$, Tanaya $D^{1}$, Anwesha $S^{2}$, Sharanya $C^{1}$ and Meenakshi $C^{3}$
}

${ }^{1}$ School of Oceanographic Studies, Jadavpur University, Kolkata 700032, West Bengal, India

${ }^{2}$ Department of Mathematics, Jadavpur University, Kolkata 700032, West Bengal, India

${ }^{3}$ Basanti Devi College, Kolkata 700029, West Bengal, India

\begin{abstract}
Sundarbans Estuarine System (SES, $21.25^{\circ}-22.5^{\circ} \mathrm{N}$ and $88.25^{\circ}-89.5^{\circ} \mathrm{E}$ ), comprising the southernmost part of the Indian portion of the Ganga-Bramhaputra delta bordering the Bay of Bengal, is India's largest monsoonal, macrotidal delta front system. Sundarbans Estuarine Programme (SEP), the first comprehensive observational programme to study tidal as well as salinity features was conducted during 18-21 March, 2011 (Equinoctial spring phase). The main objective of this program was to monitor tides and salinity characteristics within the SES. Out of 30 observation stations, spread over more than 3,600 sq km covering seven inner estuaries, we have chosen river Jagaddal, which is connected with Saptamukhi East Gulley (SEG) in the West and river Thakuran in the East, due to the fact that the station Indrapur situated on this river at location very close to Bay of Bengal represents the condition at the mouth of all seven estuaries.

Tidal elevation, salinity, bathymetry and vertical profile of salinity using CTD were measured during the observation period. Observed current data collected from different sources have been used for comparison with computed tidal current. Finally, the estuarine current, bottom drag coefficient and gradient Richardson number have also been computed. Computed values of these parameters have analyzed for interpreting variations for tidal, current and mixing feature prevailing in the estuary.
\end{abstract}

Keywords: Tidal current; Estuarine circulation; Salinity; Mixing; Sundarban; Estuary; Bottom drag coefficient

\section{Introduction}

Sundarbans Estuarine System (SES, the region lying between $21.25^{\circ}-22.5^{\circ} \mathrm{N}$ and $88.25^{\circ}-89.5^{\circ} \mathrm{E}$ ) is India's largest monsoonal, macrotidal delta-front estuarine system in the eastern coastal state of West Bengal. River Hoogly, the first deltaic offshoot of the river Ganga forms the western boundary of the SES. River Raimangal, a tributary of river Ichhamati, an easterly distributary of the Ganga forms the eastern boundary of the SES. Dense natural mangrove forests of Sundarbans in the southern fringes of the Bay of Bengal forms the southern limit. An imaginary line named Dampier-Hodges line based on 1829-1832 survey is the northern boundary of SES. North-south flowing rivers: the Saptamukhi, Thakuran, Matla, Bidya, Gomdi, Gosaba, Gona, Harinbhanga and Raimangal form the principal estuaries of SES on the east of the Hoogly as a complex network of numerous westeast interlinked channels, canals and creeks. In addition to the tidal effects at their mouths, during floods these inner estuaries accumulate considerable amount of Gangetic fresh water in their upstream along with summer monsoon rainfall which are the major driving factors in retraining the estuarine character of the SES. The rivers, water bodies, intertidal mudflats, creeks, saline swamps, sandy shoals in SES are remarkable not only for the astounding biodiversity including a wide variety of benthic and pelagic fauna (such as fish and crustaceans), spawning zone of reptiles (such as crocodiles), fisheries but also for their important role as a natural filter to pollutants released from the human settlements and industrial zone in northern reaches and major pathways for nutrient recycling. Moreover impenetrable mangrove forests acts like a protective barrier to the densely populated metropolitan city of Kolkata to its north by absorbing direct impact of cyclonic storms and surges from the Bay of Bengal to a great extent [1].

All the principal estuaries in the SES are funnel-shaped, widths converge rapidly northwards, having very wide mouths at confluences with the Bay of Bengal and following meandering courses with sharp bends. Over this distance the characteristics of the SES has shaped in these different environments (variable depth, width and stretches) by the interplay of a variety of physical processes. This investigation is a part of a series of intensive on-going study of the tidal elevations, salinity and temperature at 30 locations situated on the principal inner estuaries of the SES, conducted by Sundarbans Estuarine Programme (SEP) during 18-21 March 2011(Pre-monsoon period), 2013 and one month phase of study in August, 2015 (Monsoon period).

In the first observation programme (during 18-21 March 2011, Premonsoon period, equinoctial spring phase) in SES it was reported that estuaries have shown a great diversity of tidal forcing characteristics with different depth, width, size and shape. In general tidal range has increased from mouth to head (northwards) in all estuaries due to convergent channel geometry (funnel-shaped) and frictional effects with the variable degree and rates of amplification over the various estuarine stretches as a result of flood-dominant and ebb-dominant tidal asymmetries [1]. In such estuarine system tidal currents, salinity variation and river discharge predominates in estuarine flow pattern more than meteorological forcing (wind stress). So, the study of tidal flows and salinity structure are essential to assess a broad range of estuarine phenomena including dispersion of salinity, nutrients, pollutants, sediments and their transportation into and out of the estuary and to know how quickly the estuary responds to different

${ }^{*}$ Corresponding author: Goutam KS, School of Oceanographic Studies, Jadavpur University, Kolkata 700032, West Bengal, India, Tel: 919831282057; E-mail: gksju@yahoo.co.in

Received April 21, 2015; Accepted May 06, 2015; Published May 08, 2015

Citation: Goutam KS, Tanaya D, Anwesha S, Sharanya C, Meenakshi C (2015) Tide and Mixing Characteristics in Sundarbans Estuarine River System. Hydrol Current Res 6: 204. doi:10.4172/2157-7587.1000204

Copyright: @ 2015 Goutam KS, et al. This is an open-access article distributed under the terms of the Creative Commons Attribution License, which permits unrestricted use, distribution, and reproduction in any medium, provided the original author and source are credited. 
forcing such as tidal mixing and river discharge which affect the ecological health and the water quality $[1,2-8]$.

In this paper we are intended to study the flow pattern in the narrow tidal channel of River Jagaddal, a part of SES. Our attempt is to quantify the indicators such as tidal amplitude, tidal current, residual current (estuarine circulation), bottom drag coefficient and level of stratification which are essential to characterize the flow pattern in different channel geometry along a single stretch of a river.

\section{Study Area and Relevant Measurements}

River Jagaddal is flowing parallel to the Saptamukhi East Gullay (SEG) in the west, the stronger branch of the river Saptamukhi debouncing into the Bay of Bengal having links with the adjoining estuary of River Thakuran in the east through Dhanchi Khaal (cannel). In the northern limit (head) river Jagaddal has linked with river Barchara, river Kalchara and Pakhi Nala (Figure 1). River Barchara and river Kalchara are influenced by fresh water discharge of Hoogly river whereas Pakhi Nala is connected with water flow of river Thakuran.

In this study the data required for tidal elevation, salinity are collected from the field observation of four stations on Jagaddal: Indrapur (mouth), Dhanchi and Ramganga/Pakhirala (head).Observed current data collected from different sources have been used. These stations are chosen for their significant importance along the channel. The station Indrapur (S1) on river Jagaddal is closest (about $8 \mathrm{Km}$ north of Bay of Bengal) to the Bay of Bengal, representing the conditions at the mouth. The station Dhanchi (S2) is at the junction of river Jagaddal and river Thakuran through Dhanchi Cannel. The station Ramganga (S6) is at the junction of three different linkages of river Barchara, river Kalchara (connected to Hoogly River) and Pakhi Nala (connected to Thakuran). The station Pakhirala (S7) is in the bank of Pakhi Nala, serving as the connecting junction of river Jagaddal to river Thakuran. Both Ramganga and Pakhirala serve as the head of this channel.

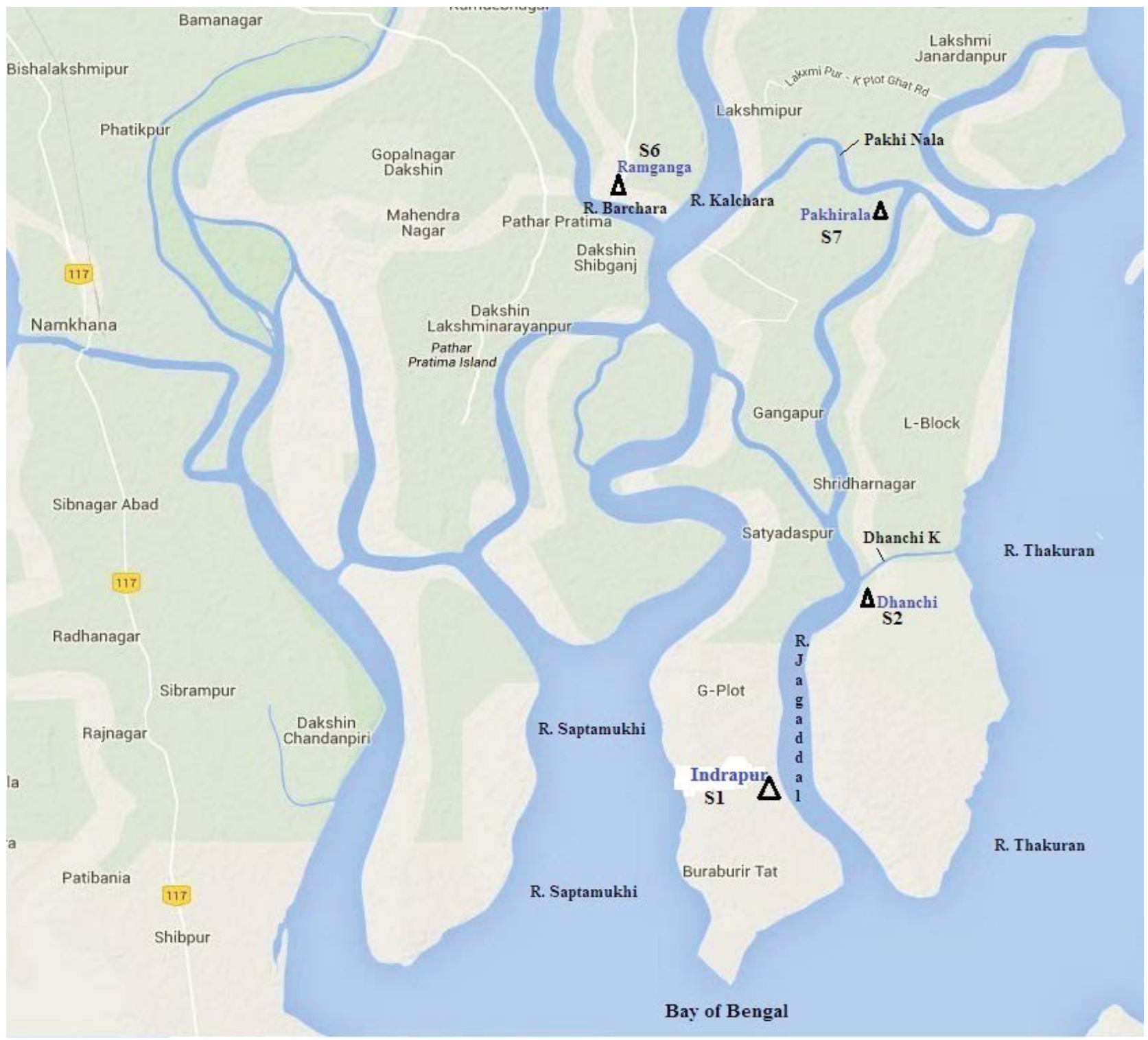

Figure 1: Study Area: Jagaddal River Estuary. Triangles show the observation stations along the river; Abbreviation R. is used to refer "River". 


\section{Methodology}

The methodology follows five steps:-

(i) The first step solves a numerical model with a given spatial distribution of friction coefficient in a channel with variable along $(-x)$ and cross $(-y)$ channel depth variation and along channel width variation to compute tidal amplitudes and velocity components.

(ii) The second step uses the velocity field computed in the previous step and applies the phase-matching method to recover the drag coefficient.

(iii) Then by using the drag coefficient estimated from the phase-matching method as a function of along-channel position in the numerical model, we have estimated the tidal current and tidal amplitude and compare with the observed amplitude. Step (i) to (iii) are repeated if the computed tidal amplitude are not close to the observed data.

(iv) Using the values of bottom drag coefficient at different depth the magnitude of residual current (estuarine circulation) is calculated.

(v) At last, the level of stratification along the channel is parameterized as the gradient Richardson number using the values of tidal current and residual current or estuarine circulation.

\section{First step: Computing depth functions}

We have assumed bathymetric functions for computational convenience, by fitting bathymetry data along cross-channel directions. Several such bathymetry profiles have been used for different segment of the river to examine the effect of complicated bathymetry. The depth function is assumed to vary in both along-(x) and cross-channel (y) directions as needed having the following form:

$$
h=b_{0}+b_{1} * \exp \left(-\frac{\left(y-\frac{D}{2}\right)^{2}}{b_{2}}\right)
$$

where $\mathrm{D}$ is the transverse coordinate, the estuary width, and $\mathrm{b}_{0}, \mathrm{~b}_{1}$, $\mathrm{b}_{2}$ are the parameters that adjust the depth profile and vary with $\mathrm{x}$. The width $\mathrm{D}$ is allowed to vary from 0 (at mouth) to maximum value for each of the transect starting from mouth to head of the channel.

\section{Second step: Solving numerical model}

We have used the depth-averaged hydrodynamic model for shallow tidal estuaries (maximum water depth is on the order of a few tens of meters) to compute tidal current and amplitude as described by $\mathrm{Li}$ et al. $[9,10]$ to study the variation of intratidal flow field in James river estuary. This method is a modification of the adjoint variational method, the full-scale assimilative numerical models to compute tidal current and amplitude with variable bottom drag coefficient in Chesapeake Bay by Ulman and Wilson et al., Spitz and Klinck et al. $[6,11]$.

We have assumed the estuarine geometry as a curved channel with variable width and an arbitrary lateral depth variation. By following approach similar to Li et al. [7], due to anisotropy of width and depth variation, we have to opt for numerical approach. The $\mathrm{x}$ axis is taken to lie along the river boundary and points toward the head of the estuary. The $\mathrm{y}$ axis lies along the open boundary at $\mathrm{x}=0$.

The depth-averaged, shallow water momentum and continuity equations [Li and Levinson] [9] are numerically solved to obtain the tidal amplitude and tidal current:-

$$
\begin{aligned}
& \frac{\partial u}{\partial t}+u \frac{\partial u}{\partial x}+v \frac{\partial u}{\partial y}-f v=-g \frac{\partial \varsigma}{\partial x}-\beta \frac{u}{h}+\frac{\beta}{h^{2}} u \varsigma \\
& \frac{\partial v}{\partial t}+u \frac{\partial v}{\partial x}+v \frac{\partial v}{\partial y}+f u=-g \frac{\partial \varsigma}{\partial y}-\beta \frac{v}{h}+\frac{\beta}{h^{2}} v \varsigma \\
& \frac{\partial \varsigma}{\partial t}+\frac{\partial(h+\varsigma) u}{\partial x}+\frac{\partial(h+\varsigma) v}{\partial y}=0
\end{aligned}
$$

Where u:- longitudinal velocity, v: lateral velocity, $\varsigma$ : elevation, $\mathrm{h}$ : water depth, $\mathrm{x}$ : longitudinal coordinate, $\mathrm{y}$ : lateral coordinate, $\mathrm{t}$ : time, $\beta$ : friction coefficient, f: coriolis parameter, g: gravitational acceleration.

The friction coefficient $\beta$ is defined by Proudman and Parker $[12,13]:-$

$$
\beta=\frac{8 C_{D} U_{O}}{3 \pi}
$$

where $\mathrm{C}_{\mathrm{D}}$ and $\mathrm{U}_{0}$ are bottom drag coefficient and magnitude of longitudinal velocity respectively. The friction coefficient $\hat{a}$, a function of $\mathrm{x}$ and $\mathrm{y}$, is dependent on the velocity amplitude and the bottom drag coefficient. Spatial distribution of $C_{D}$ for every segment of the channel and also the interpolated longitudinal velocity $\mathrm{U}_{0}$ along the channel from observed current data are used to provide initial values for $C_{D}$ and then $\beta$ to solve equation (2) numerically.

\section{Recovering bottom drag coefficient}

In depth-averaged hydrodynamic model, the intensity of the overall tidal energy dissipation is related to mainly bottom drag coefficient for the major tidal frequency component $[9,10]$. Again we have assumed that the bathymetry effect alone will be able to produce significant spatial variation in bottom drag coefficient with an effect on tidal current and amplitude in a tidal channel. Hence we have chosen arbitrary along and across channel depth variations with the emphasis on the effect of channel-shoal configuration and bottom slopes.

Using the computed results for tidal current and amplitude from numerical simulation of depth-averaged, shallow water momentum and continuity equations (2), spatial variation of $C_{D}$ in tidal channels with significant lateral variation of depth is estimated by applying the phase-matching method [10]. The calculation involves the following steps:

(a) The amplitude and phase of the computed tidal current $\left(\varphi_{U}\right)$ are obtained by harmonic decomposition of horizontal velocity.

(b) The phase of the tidal current is then fitted to a quadratic function of the water depth to obtain the phase of the pressure gradient $\varphi_{A x}$.

(c) From the phase relationship of the longitudinal momentum equation, the drag coefficient is calculated as a function of the transverse position using the following formula:

$$
C_{D}=\frac{3 \pi \sigma h}{8 U_{o \tan \left(\varphi_{A x-\varphi_{U}}\right)}}
$$

Where $\sigma$ is the angular frequency of the semi-diurnal tide (M2 tide for this study), $h$ is the undisturbed water depth, $\mathrm{U}_{0}$ is the amplitude 
of the tidal current, $\varphi_{U}$ is the phase of the computed tidal current and $\varphi_{A X}$ is the phase of the pressure gradient.

\section{Estimation of residual or estuarine circulation}

Pritchard [14] first introduced the concept of "residual" or estuarine circulation driven by horizontal salinity gradient, a key dynamical variable that makes estuaries different from any other marine environment and plays a key role in maintaining salinity stratification in estuary which inhibits vertical mixing and leads to one way of classifying estuaries based on strength of stratification: well mixed, partially mixed, highly stratified and salt edge. He pointed out that if the vertically varying horizontal currents are measured through the course of the tidal cycle, and then averaged, the estuarine circulation would be revealed, though the tidal currents are typically much stronger the estuarine circulation.

Using tidal current $U_{T}$ we have calculated the magnitude of estuarine circulation, $U_{e}$ expressed as (Geyer et al.,) [15]:

$$
U_{e}=a_{0} \frac{\beta_{s} h^{2} g \frac{\partial s}{\partial x}}{C_{D} U_{T}}
$$

Where $\mathrm{a}_{0}$ is a dimensionless constant related to turbulent momentum flux, $\beta_{s}$ is the coefficient of saline contraction, $g$ is the acceleration of gravity, $h$ is the water depth, $\mathrm{U}_{\mathrm{T}}$ is the tidal velocity.

\section{Estimation of level of mixing}

Numerous studies have undertaken to analyze importance of salinity gradient, stratification and tidal currents in estuarine circulation. Both river discharge and mixing are crucial for the different tidal flushing process and tide-induced transport of materials in flood and ebb conditions. During the flood tide when the more saline sea water is coming into estuary with a faster advancement at the surface, the heavier salt water on the surface promotes vertical mixing to reach a more stable state. During ebb tide when the fresher less saline estuarine water is going out of the estuary with a faster advancement at the surface on the heavier more saline water at bottom, a more stable water column is formed suppressing vertical mixing. The sensitive dependence of stratification on tide also has been revealed in a number of studies of the spring-neap variation of tidal cycle with stratification with maximal tidal mixing and minimum stratification during spring tides $[7,15]$.

Geyer et al. [15] obtained the top-to-bottom salinity difference, $\Delta s$ is estimated from $\frac{\partial s}{\partial x}$, the horizontal salinity gradient obtained from observed salinity data in Hudson estuary,

$$
\Delta s=a_{1} \frac{\frac{\partial s}{\partial x} h U_{e}}{C_{D} U_{T}}
$$

Where $\mathrm{a}_{1}$ is a constant that depends on the shape of salinity and velocity profile, $\frac{\partial s}{\partial x}$ is the horizontal salinity gradient and $C_{D}$ is the bottom drag coefficient.

To quantify the importance of stratification on mixing, the gradient Richardson number $R_{i T}$ is estimated which is defined as the ratio between vertical salinity difference and tidal velocity,

$$
R_{i T} \frac{\beta_{S} g \Delta s h}{U_{T}^{2}}
$$

On the basis of the estimated value of gradient Richardson number we have differentiated the level of mixing along the channel.

\section{Results and Discussions}

During observation period of 18-21 March 2011 (Pre-monsoon period) an increased trend in tidal range from mouth (Indrapur) to head (Ramganga, Pakhirala) was observed along Jagaddal. But interestingly, a decrease in tidal range was observed between Indrapur and Dhanchi (Figure 2: near the junction of Jagaddal and Dhanchi Canal (Chatterjee et al., [1]. Some striking features regarding salinity variation was also observed during observation where the salinity decreases from mouth to head upto Ramganga, but it increases from Ramganga to Pakhirala (Figure 3).

From Indrapur towards Dhanchi, at the junction of Jagaddal and Dhanchi canal, the depth has decreased suddenly (Figure 4). In this shallow region, the stronger tidal current has observed. Here the width of the channel has increased due to linking channel with two rivers

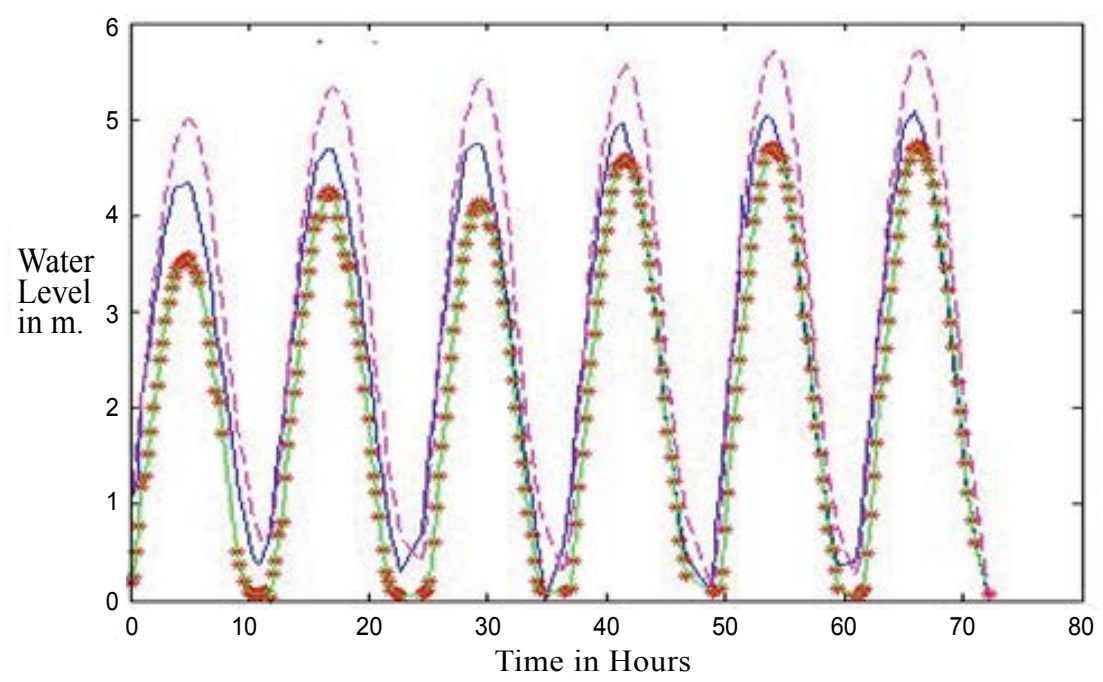

Indrapur.

Dhanchi

Ramganga

Pakhirala

Figure 2: Observed water level variation in four observation stations. 
Citation: Goutam KS, Tanaya D, Anwesha S, Sharanya C, Meenakshi C (2015) Tide and Mixing Characteristics in Sundarbans Estuarine River System. Hydrol Current Res 6: 204. doi:10.4172/2157-7587.1000204

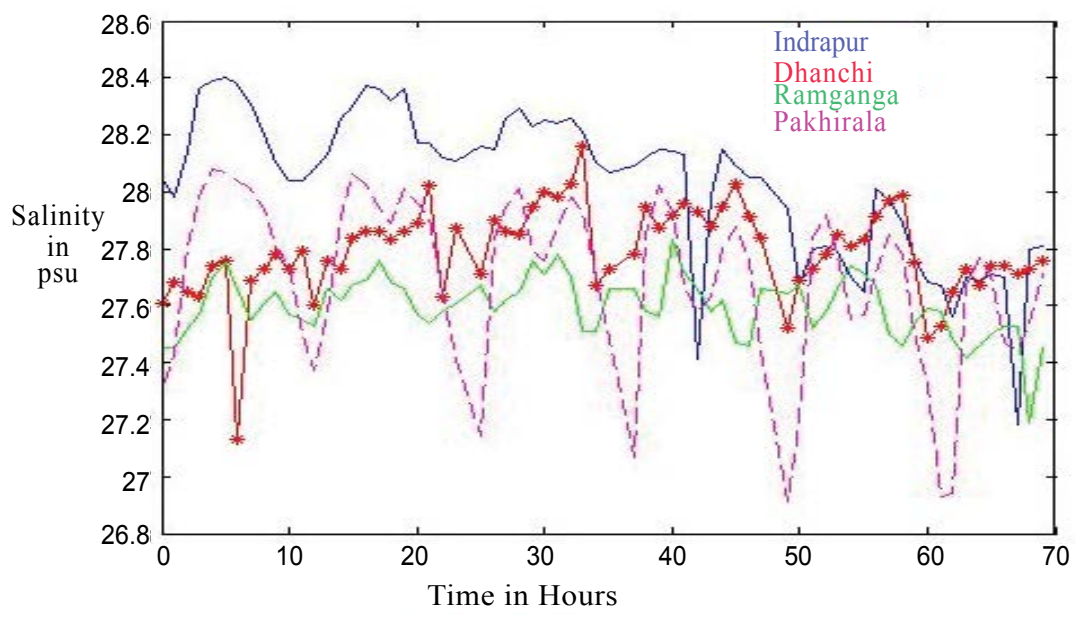

Figure 3: Observed salinity variation in four observation stations.

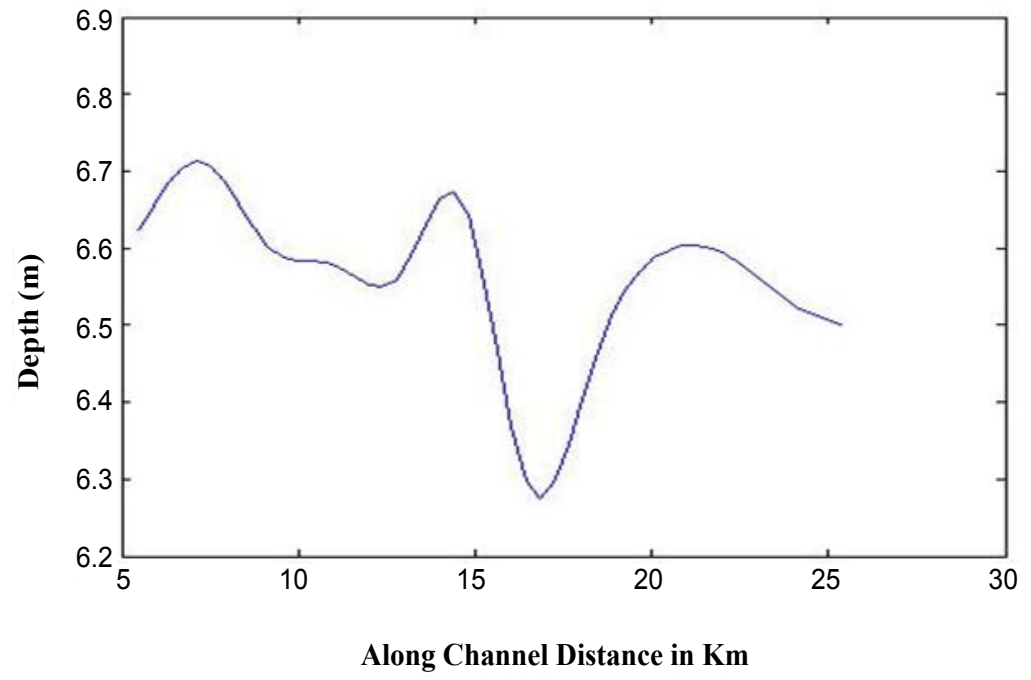

Figure 4: Depth distribution along the channel.

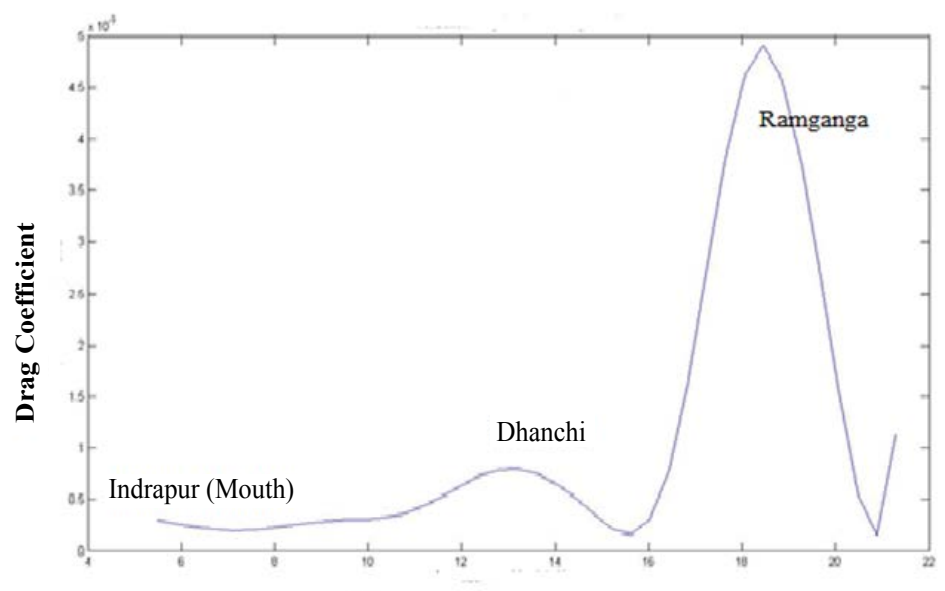

Along channel distance in $\mathbf{k m}$

Figure 5: Drag coefficient variation along the channel. 
(Saptamukhi, in the west) and Thakuran, in the east connected through Dhanchi canal. In addition, the bottom drag coefficient (Figure 5) has increased suddenly after this junction. With the combined effect of increased $C_{D}$ and river width, the water level (Figure 2) and tidal current (Figure 6) has dropped after this point.

Near the west bank of Jagaddal, the cross channel current is stronger and generates stronger residual circulation (Figure 7). The estuarine current has started to increase from Dhanchi to Indrapur. Vertical salinity gradient has increased due to landward advection of denser and more saline seawater at bottom and seaward advection of fresh riverine water on the top layer. As a result, an increase in gradient Richardson number $(>0.25$, Figure 8$)$ from Dhanchi to Indrapur (towards the sea) has found which indicates that the stratification has already started.

Along the channel from Dhanchi to Ramganga, there are three adjoining rivers: Kalchara, Barchara and Pakhi Nala which draw large amount of less saline water from Hoogly. Depth has increasing trend here and tidal current tends to take a sharp rise. From CTD cast it is observed that vertical gradient of salinity over this stretch of the river is negligible. The gradient Richardson number at this region initiates strong mixing by making stratification negligible (the channel in this area acts as a well-mixed estuary) with an increased bottom drag coefficient along this portion of the river. The increased river inflow (through linked rivers or channels) increases the tidal current and amplitude suppressing the role of drag coefficient (opposite to the observations in Dhanchi). Similar type of phenomenon was reported by $\mathrm{Li}$ et al. in James river estuary where increased river discharge has limited tidal mixing, lowering the bottom drag coefficient. For this reason, decrease in tidal current and amplitude due to large value of bottom drag coefficient have not observed here in contradiction with Dhanchi. A small peak in estuarine circulation is found due to this limited effect of drag coefficient.

\section{Conclusion}

The main intension of this study is to interpret the cause about the

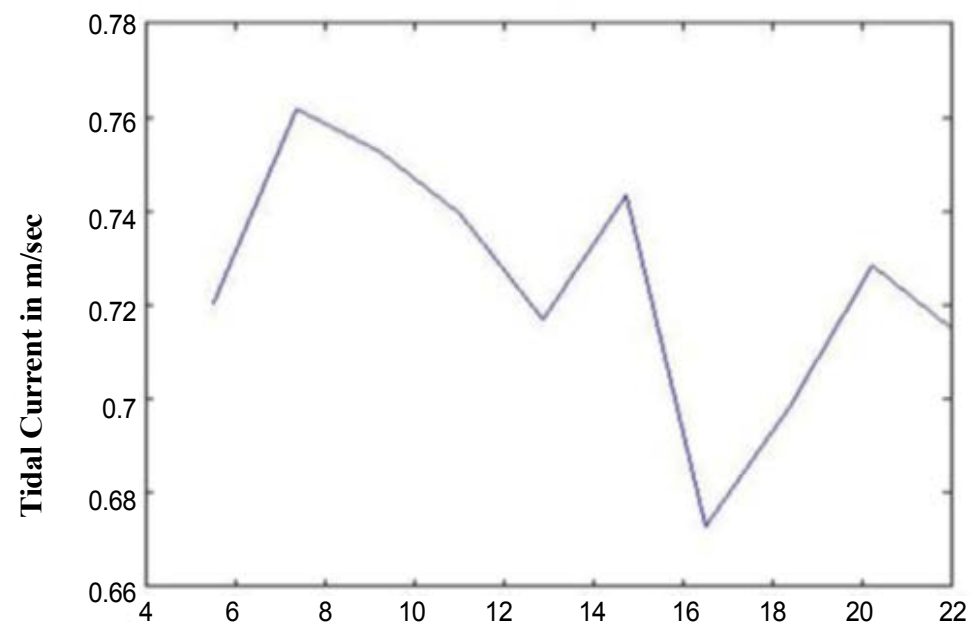

Along Channel Distance in $(\mathrm{km})$

Figure 6: Tidal current variation along the channel.

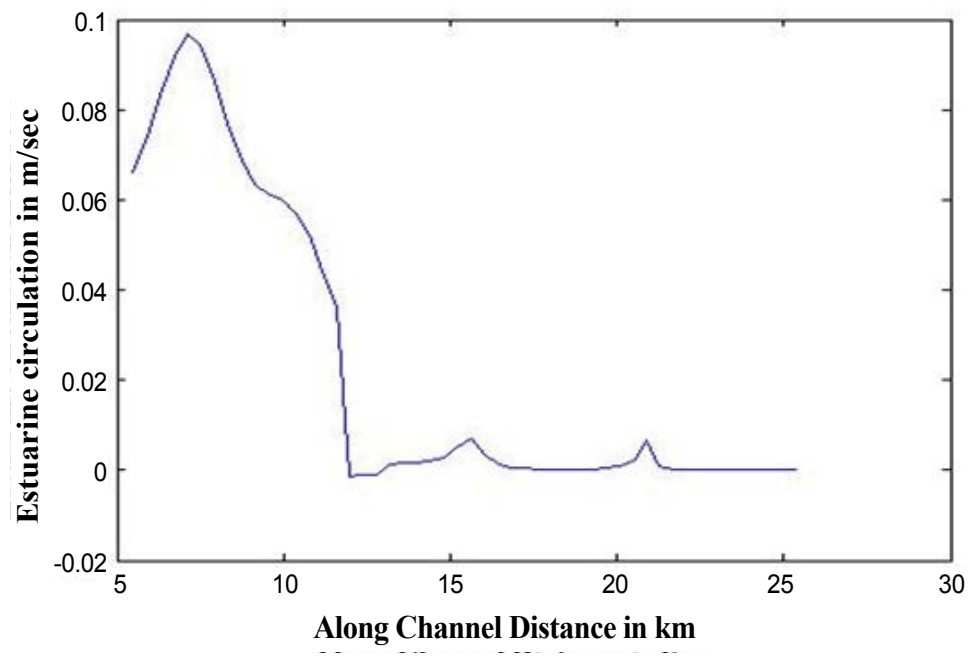

Figure 7: Estuarine current variation along the channel. 
Citation: Goutam KS, Tanaya D, Anwesha S, Sharanya C, Meenakshi C (2015) Tide and Mixing Characteristics in Sundarbans Estuarine River System. Hydrol Current Res 6: 204. doi:10.4172/2157-7587.1000204

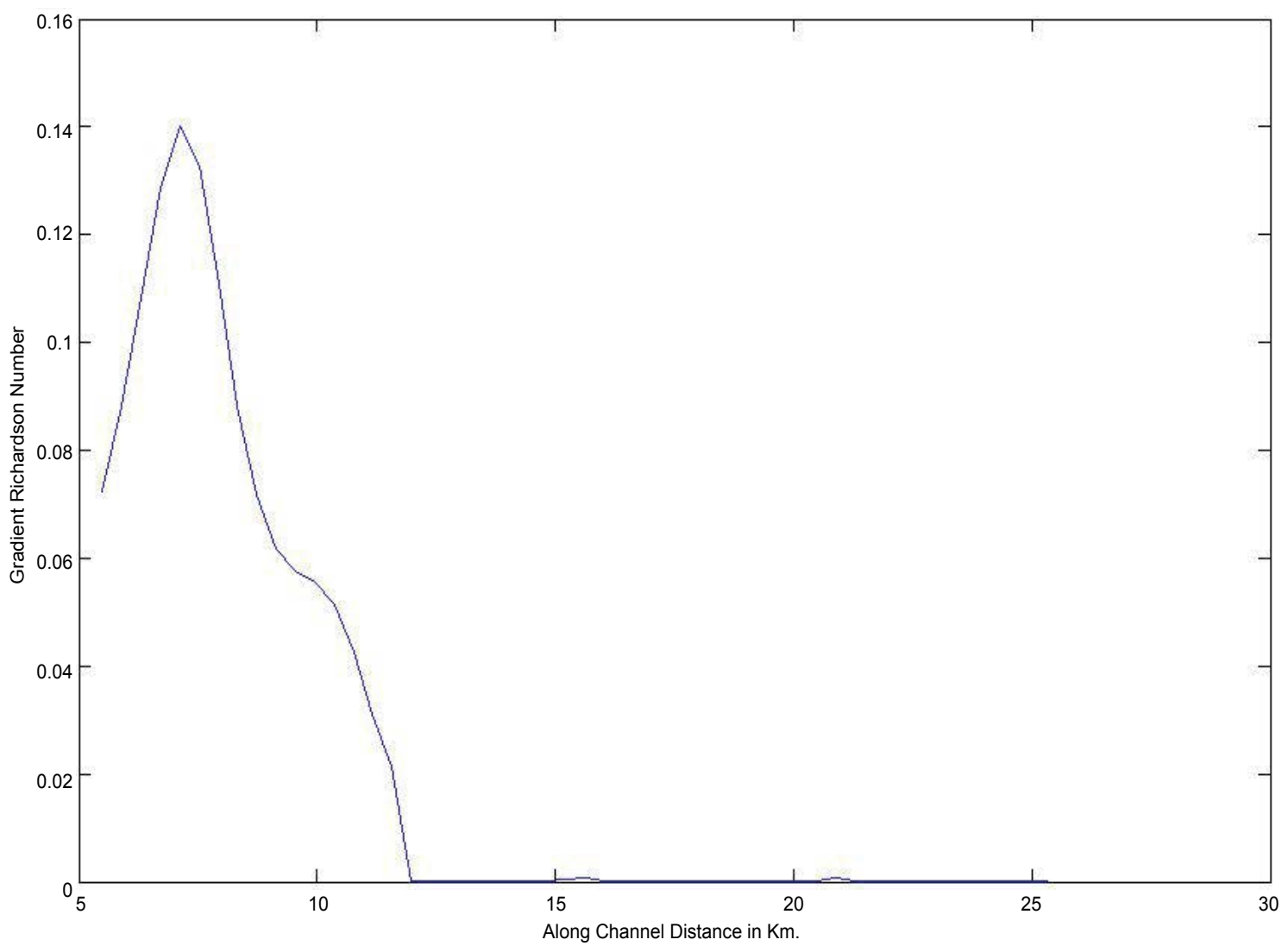

Figure 8: Gradient Richardson number variation along the channel.

variation of water elevation at several locations on Jagaddal. Crosschannel flow (west-east) is a dominant feature in this region (though rigorous measurement on this aspect is not available except some cross channel current measurement near river junction). Variational features of bottom drag coefficient and estuarine current, due to inflow through two intervening channels near Dhanchi, one connected with Thakuran and other connected with Saptamukhi, contribute to tidal amplitude and current variation. River Jagaddal (as observed from, gradient Richardson number variation) also shows stratification characteristics from Indrapur to Dhanchi. But beyond Dhanchi upto the head (further north) it exhibits a zone of strong mixing. This zone of strong mixing is indicative of the feature of considerable fresh water flow from river Hoogly. All the salient findings corroborated in above mentioned statements have been observed with considerable elaboration in our discussion part.

\section{Acknowledgements}

This work has been supported by the Sundarbans Estuarine Programme (SEP) funded by Indian national Centre for Ocean Information Services (INCOIS), Ministry of Earth Sciences, Government of India. The authors are grateful to Dr. Meenakdhi Chatterjee, Project Coordinator of Sundarbans Estuarine Programme (SEP) for appreciable assistance and for providing data and other necessary information.

\section{References}

1. Chatterjee M, Shankar D, Sen GK, Sanyal P, Sundar D (2013) Tidal variation in the Sundarbans Estuarine System, India. J Earth Syst Sci 122(4): 899-933.

2. Jay DA, Smith JD (1990) Residual circulation in shallow estuaries: 1. Highly stratified, narrow estuaries J Geophys Res 95: 711-731.
3. Jay DA, Smith JD (1990) Residual circulation in shallow estuaries. 2. Weakly stratified and partially mixed, narrow estuaries. J Geophys Res 95: 733-748.

4. Valle-Levinson A, Li C, Royer TC, Atkinson LP (1998) Continental Shelf Research 18: 1157-1177.

5. Mac Cready $P$ (1999) Estuarine adjustment to changes in river flow and tidal mixing. J Phys Oceanogr 29: 708-726.

6. Spitz YH, Klinck JM (1998) Estimate of bottom and surface stress during a spring-neap tide cycle by dynamical assimilation of tide gauge observations in the Chesapeake Bay. J Geophys Res 103: 12761-12782.

7. Li C (2006) Modeling of Bathymetry Locked Residual Eddies in Well mixed Tidal Channels with Arbitrary Depth Variations, J Phys Oceanogr 36: 19741993.

8. Li C, Swenson E, Weeks E, White JR (2009) Asymmetric tidal straining across an inlet: Lateral invertsion and variability over a tidal cycle, Estuarine, Coastal and Shelf Science 85: 651-660.

9. Li Chunyan, Valle-Levinson A (1999) A two-dimensional analytic tidal mode for a narrow estuary of arbitrary lateral depth variation: The intratidal motion. J Geophys Res 104: 23525-23543.

10. Li C, Valle-LA, Atkinson, LP, Wong K, Lwiza K (2004) Estimation of drag coefficient in James River estuary using tidal velocity data from a vessel-towed ADCP, J Geophys Res 109: C3.

11. Ullman D, Wilson RE (1998) Model parameter estimation from data assimilation modeling: Temporal and spatial variability of the bottom drag coefficient. J Geophys Res 103: 5531-5549.

12. Proudman J (1953) Dynamical Oceanography, Methuen, New York, p. 409.

13. Parker BB (1984) Frictional effects on the tidal dynamics of shallow estuary, (Ph.D. dissertation) Johns Hopkins Univ., Baltimore, pp. 291.

14. Pritchard DW (1956) The dynamic structure of a coastal plain estuary. J Mar Res 15: 33-42.

15. Geyer WR (2001) Estuarine salinity structure and stratification. 